\title{
Facts are few, comment is free
}

\author{
Kamran Abbasi international editor, The BMJ
}

Six in 10 Scottish doctors in a survey conducted by The BMJ in July and August planned to vote against independence for Scotland (BMJ 2014;349:g5072, doi:10.1136/bmj.g5072).

Repeating that survey today might produce different results, as the campaign for independence gathers supporters. Our survey was a snapshot of the mood of the Scottish medical profession that focused on health, but doctors against independence were still mostly concerned about the future of Scotland's economy. Worries about medical research in Scotland and the undesirability of a new regulatory body for the profession were next. Doctors in favour of independence believed that healthcare and social care would improve and that autonomy was important for Scotland's healthcare system. Interestingly, these secessionists believe that an independent Scotland's economy is more likely to prosper.

We are all guessing, of course. In the political realm facts are few and comment is freely given. Evaluations of national and international reforms - whether in specific areas such as healthcare or wider political reorganisations - are either absent or piecemeal. The benefits and harms to health of being part of the United Kingdom or the European Union need further inquiry. We do know that with any union, like a marriage, come new rules and regulations that may not quite deliver what they promised.

The regulation of medical devices, for example, remains a problem. A systematic review published this week finds no benefit of improved clinical outcomes from five hip and knee replacement technologies marketed as "advances" and raises safety concerns (BMJ 2014;349:g5133, doi:10.1136/bmj.g5133). Editorialists Aaron Kesselheim and Prashant Rajan note that these data expose the limited regulatory oversight of incremental device innovations in Europe, the United States, and other countries (BMJ 2014;349:g5303, doi:10.1136/bmj.g5303). A lack of testing puts patients at risk. Regulators such as the US Food and Drug Administration and the European Medicines Agency must be more circumspect about allowing new design changes before the previous alterations have been properly evaluated. Better research and more post-marketing surveillance by manufacturers are needed.

Another responsibility of the European Union is to coordinate national injury surveillance and evaluate the effectiveness of injury prevention initiatives across member states. Coordinated collection of injury data in Europe is now threatened because countries, including the United Kingdom, are no longer committed to the project. Graham Kirkwood and colleagues argue that injury surveillance is central to reducing harm from injuries and that the UK must honour its commitment to the European initiative by investing in and improving the quality of its data collection (BMJ 2014;349:g5337 doi:10.1136/bmj. g5337).

Investment has been made in the NHS's Cancer Drugs Fund, an alternative route to funding new cancer treatments that fail to be approved by the National Institute of Health and Care Excellence (NICE). Andrew Jack describes how funding for this initiative diverts money from other health budgets, exasperates NICE, creates a drugs bill dilemma for the new chief executive of the NHS, and manages to please many but not all drug manufacturers (BMJ 2014;349:g5524, doi:10.1136/ bmj.g5524). Scotland, acting independently, has declined to introduce a cancer drugs fund until now.

Scotland might have acted differently too in the case of Ashya King, whose parents removed him from an English hospital to seek treatment in Europe (BMJ 2014;349:g5570, doi:10.1136/ bmj.g5570). Two Observations articles this week discuss the importance of good communication between staff, parents, and authorities (BMJ 2014;349:g5563, doi:10.1136/bmj.g5563; 2014;349:g5567, doi:10.1136/bmj.g5567). If Scotland does leave the United Kingdom, the "no" campaigners may also wish they had communicated their message more clearly.

\section{Follow Kamran Abbasi on Twitter @KamranAbbasi}

Cite this as: BMJ 2014;349:95586

๑ BMJ Publishing Group Ltd 2014 